Etnográfica

Revista do Centro em Rede de Investigação em

Antropologia

vol. 24 (1) | 2020

Vol. $24(1)$

\title{
El obrero inmigrante en el ramo de la construcción: un sujeto simultáneamente merecedor e inmerecedor de su precariedad
}

The immigrant construction worker as a subject both deserving and underserving his precarious condition

\section{Xavier García Curado}

\section{(2) OpenEdition}

\section{Journals}

Edición electrónica

URL: https://journals.openedition.org/etnografica/8547

DOI: 10.4000/etnografica.8547

ISSN: 2182-2891

\section{Editor}

Centro em Rede de Investigação em Antropologia

Edición impresa

Fecha de publicación: 1 febrero 2020

Paginación: 245-264

ISSN: 0873-6561

\section{Referencia electrónica}

Xavier García Curado, «El obrero inmigrante en el ramo de la construcción: un sujeto simultáneamente merecedor e inmerecedor de su precariedad», Etnográfica [En línea], vol. 24 (1) | 2020, Publicado el 26 febrero 2020, consultado el 19 enero 2022. URL: http://journals.openedition.org/etnografica/8547 ; DOI: https://doi.org/10.4000/etnografica.8547

\section{(c) (7) \&}

Etnográfica is licensed under a Creative Commons Attribution-NonCommercial 4.0 International License. 


\section{El obrero inmigrante en el ramo de la construcción: un sujeto simultáneamente merecedor e inmerecedor de su precariedad}

\section{Xavier García Curado}

En los últimos 20 años aproximadamente, el sector de la construcción español ha experimentado un altibajo sin precedentes, plasmado en los fenómenos de la burbuja inmobiliaria (1997-2007) y la crisis inmobiliaria (2007-2018). En tiempos de expansión, dicho sector absorbió grandes cuotas de mano de obra, tanto autóctona como migrada. Llegado el estallido de la burbuja y la consecuente destrucción masiva de empleo, muchos obreros se vieron sumidos en la precariedad. Con la crisis, se impuso para los trabajadores una lógica de competencia para acceder a los pocos puestos de trabajo que permanecieron en el ramo. Este artículo parte de un trabajo etnográfico realizado en distintos contextos cotidianos de obreros de la construcción de Barcelona y su área metropolitana. El propósito es analizar el contenido de ciertas realidades sociolaborales que, simultáneamente, señalan al obrero inmigrante como merecedor e inmerecedor de su precariedad.

PALABRAS CLAVE: obrero, inmigrante, sector de la construcción, crisis, (in)merecimiento.

The immigrant construction worker as a subject both deserving and underserving his precarious condition - In the last 20 years approximately, the Spanish construction sector has experienced an unprecedented up and down, reflected by the phenomena of the housing bubble (1997-2007) and the housing crisis (2007-2018). During the economic expansion times, the construction sector absorbed a large amount of labor, both autochthonous and migrant workers. When the bubble burst, a lot of employment was destroyed and many workers fell into a precarious situation. Because of the crisis, a competitive logic to get a job in the construction sector was imposed to the workers. This article is based on ethnographic work carried out in different everyday-life contexts of construction workers of Barcelona and its metropolitan area. Our goal is to analyze the content of some sociolaboral realities which, simultaneously, point out the immigrant worker as deserving and undeserving of his precariousness.

KEYWORDS: worker, immigrant, construction sector, crisis, (un)deservingness.

GARCÍA CURADO, Xavier (xavigarreta@hotmail.com) - Grupo de Estudios sobre Reciprocidad (GER), Departamento de Antropología Social y Cultural, Universitat de Barcelona, España. 


\section{INTRODUCCIÓN}

Este artículo se enmarca en mi investigación doctoral. ${ }^{1}$ En ella me fijo en la evolución de la cotidianidad sociolaboral de los obreros de la construcción de Barcelona y su área metropolitana durante la etapa de crisis. Los datos presentados se han obtenido gracias al trabajo de campo realizado durante más de tres años en distintos espacios cotidianos de los trabajadores - obras, cursos de formación, reuniones sindicales y lugares de ocio - y mediante distintas herramientas etnográficas - entrevistas en profundidad, observación y grupos de discusión -. De las múltiples líneas de investigación emergentes en el trabajo de campo, la que motiva este artículo es la de las concepciones de (in)justicia de los obreros en contexto de recesión, concretamente en relación al acceso a los escasos puestos de trabajo y a las dificultades para paliar la ola de precariedad. Para abordarla, usaremos la distinción entre las esferas de (in)justicia redistributiva, aludiendo a desigualdades materiales, e (in)justicia de reconocimiento, aludiendo a la desvalorización o estigmatización de identidades culturales (Fraser 2000). El concepto de merecimiento (Chauvin, Garcés-Mascareñas y Kraler 2013, Chauvin y Garcés-Mascareñas 2014) será clave en este ejercicio, pues será el vehículo mediante el cual nos aproximaremos al quid de la cuestión. En un estadio de austeridad y constreñimiento del mercado, los mismos obreros se cuestionan: "¿Quién merece acceder preferentemente a los escasos puestos de trabajo?" Y derivado de la pregunta anterior: "¿Quién es menos merecedor de la precariedad que se ha extendido con la crisis?" Las preguntas invitan o bien a una jerarquización de sujetos de más a menos merecedores, o bien a un establecimiento de fronteras que separen los trabajadores merecedores de los inmerecedores. En este ejercicio de ordenación y/o exclusión, uno de los criterios que constantemente movilizan los implicados es la distinción entre las comunidades morales (Yack 2012) de "obreros autóctonos" y "obreros inmigrantes".

En cuanto a la estructura del artículo, en el próximo apartado expondremos una necesaria contextualización. Hay ciertos fenómenos estructurales

l La investigación en base a este articulo forma parte del proyecto "Concepciones Populares de la Justicia Social ante la Crisis y las Políticas de Austeridad" (CSO2015-67368-P), financiado por el Ministerio de Economía y Competitividad español y el Fondo Europeo de Desarrollo Regional (Feder), 2016-2018, vinculado al Grupo de Estudios sobre Reciprocidad (GER) de la Universidad de Barcelona. 2 Aunque utilicemos la distinción emic entre "trabajador autóctono" y "trabajador inmigrante" para organizar el análisis, esta debe ser matizada. Cuando hablemos del "obrero inmigrante" nos referimos a las personas vinculadas a las nuevas olas de migración laboral internacional que, a finales del siglo XX y principios del XXI, llenaron las obras de Barcelona y su área metropolitana. Las regiones de origen eran Norte de África, América Latina, Europa del Este y Asia Meridional. Con "obrero autóctono" nos referimos al trabajador nacido en el Estado Español. El importante matiz recae en que la mayoría de los informantes a los que nosotros etiquetamos como autóctonos no dejan de ser inmigrantes o hijos de inmigrantes nacionales de la década de los 60 y 70, provenientes principalmente del Sur de España. 
vinculados, por un lado, al sistema capitalista contemporáneo en general y, por otro lado, a la organización de la producción en el ramo de la construcción, que subyacen y dan forma a la información etnográfica posteriormente presentada. A continuación, desarrollaremos el concepto de comunidad moral y lo situaremos en los relatos de vida de los obreros. Los procesos de creación de grupos simbólicos y la posterior atribución de cualidades morales a cada uno de ellos son ingredientes indispensables para el surgimiento de concepciones de merecimiento. En tercer lugar, nos adentraremos en la discusión etnográfica sobre el merecimiento en relación al acceso a los puestos de trabajo en tiempos de crisis. En dicha discusión, distinguiremos entre tres posicionamientos ideológicos generales detectados en el trabajo de campo: el primero es el que cataloga al trabajador inmigrante como inmerecedor por ser un competidor desleal; el segundo es el que cataloga a todos los trabajadores como merecedores, aunque alterizando a los inmigrantes; el último es el que parte de la noción de necesidad para acabar en una concepción integradora del merecimiento. Finalmente, cerraremos el artículo con las conclusiones.

\section{CONTEXTUALIZACIÓN Y CONDICIONAMIENTOS ESTRUCTURALES}

Los discursos y realidades analizadas en este artículo están fuertemente sujetos a los acontecimientos macroeconómicos que han sacudido el ramo de la construcción barcelonés - y español - en los últimos años. Por ende, la adecuada comprensión de las concepciones de (in)justicia y merecimiento vinculadas a cotidianidades concretas siempre dependerá de que, a la vez, se establezca un dialogo con el contexto socioeconómico general. Naredo (2010: 4) señala que la burbuja inmobiliaria en España empezó en 1997 y terminó el último trimestre de 2007. La construcción siempre se ha caracterizado por ser un sector con un marcado comportamiento cíclico, pero en los últimos 20 años hemos visto como la larga duración de la pasada etapa de bonanza incitó a que se considerara como un estado normal y permanente. "Se olvidó que la intensidad del auge suele presagiar la intensidad del declive" (Naredo 2009: 118). En la

3 Según el Instituto de Estadística de Cataluña, entre los años 2001 y 2007 el sector de la construcción barcelonés absorbió 88.300 trabajadores nuevos, pasando de tener una población ocupada de 187.100 a 275.400. Por el contrario, entre 2007 y 2014 se expulsa a 156.200 trabajadores del sector, es decir, más de la mitad del total de obreros (véase "Población ocupada. Por sectores. Provincias", Instituto de Estadística de Cataluña, 2019, disponible en < https:/www.idescat.cat/pub/?id=aec\&n= $306 \& l a n g=e s>$, última consulta en febrero de 2020). En cuanto a los trabajadores extranjeros, según la Diputación de Barcelona, dentro del periodo 2006-2012, el paro registrado de este grupo crece del $15 \%$ al 25\%, representando el mayor aumento de entre todos los sectores económicos de la provincia de Barcelona (véase "Paro registrado, estrangeros: períodos por grandes sectores", Diputación de Barcelona, 2019, disponible en < https:/www.diba.cat/hg2/presentacioProv.asp?prId=1674\&idioma $=$ cat $\&$ periode $\mathrm{I}=2006 \&$ mes $\mathrm{I}=1$ \& periode $2=2012 \&$ mes $2=1$ \& format $=$ pantalla $>$, última consulta en febrero de 2020). 
expansión de la burbuja inmobiliaria subyacen factores como la sobreproducción y la compraventa de riquezas preexistentes; la dimensión especulativa poseyó gran parte de las inversiones efectuadas durante el auge. En términos laborales, las principales implicaciones fueron una absorción masiva de fuerza de trabajo en el ramo y el empeño generalizado por aumentar al máximo exponente la producción de bienes inmobiliarios. Así, se podía extraer beneficio mediante la venta de dichos bienes en un mercado inflacionario.

Como nos indica Araghi (2009), nos encontramos frente a una constante neoliberal en la que se combinan procesos de desposesión y expolio en economías del Sur global y dinámicas de apropiación de fuerza de trabajo migrada en el Norte global - en este caso, Barcelona -. Durante los años de auge inmobiliario, las obras de Barcelona y su área metropolitana fueron los espacios en los que muchos de los recién llegados encontraron sus primeras remuneraciones. Esto se debe a que el ramo de la construcción ha sido históricamente un sector iniciático en el que se facilita que cualquier persona, aun sin formación o conocimiento del oficio, pueda realizar tareas de limpieza y peonaje básico:

"Para muchos inmigrantes la construcción es su primer trabajo al llegar a la ciudad, el inmigrante coge el trabajo de peón en la construcción como algo momentáneo, por más que luego se eternice en él. La construcción se entiende para muchos trabajadores como un 'sector puente' desde el que tratar de hacer el salto a sectores con mejores condiciones laborales y sueldos [...]. [Los inmigrantes] se ocuparon de los trabajos más repetitivos, que requerían mayor esfuerzo físico y menos cualificación" (Mota 2010: 28-29).

En este fragmento, Mota nos habla del sector de la construcción de Barcelona de los años 70. Los inmigrantes que menciona son los autóctonos de hoy, que entonces venían principalmente del Sur de España. Aun así, su relato es totalmente aplicable a las realidades vividas por las nuevas olas de migración internacional que llenaron las obras de Barcelona y su área metropolitana entre finales de los 90 y los 2000. Por lo tanto, la realidad sociolaboral que analizamos en este artículo empieza a sentar sus bases durante la burbuja, concretamente mediante la comentada atracción de grandes cuotas de mano de obra - tanto migrada como autóctona -.

Los procesos de acumulación de capital que se generaban en el mercado inmobiliario reunieron en el ramo de la construcción una cantidad histórica de fuerza de trabajo. Miles de trabajadores eran movilizados en las obras de Barcelona y ciudades de alrededor. Fue entonces cuando entraron en juego ciertas especificidades vinculadas a la organización del trabajo en las obras, destacadas ya por otros autores (Del Águila Lacoste 2015; Pink, Tutt y Dainity 2012; De la Garza Toledo 2012), que resultaron altamente determinantes en 
el proceso de creación de comunidades morales y, una vez llegada la crisis, de concepciones de merecimiento. La construcción es un sector constituido por un conjunto heterogéneo de obras, oficios y empresas, lo que ha llevado a algunos/as pensadores/as a declarar que contiene una "fragmentación estructural" (Pink, Tutt y Dainity 2012: 2). En lo que respecta a las obras, la fragmentación se aprecia con la presencia de varios grupos de trabajo - conocidos popularmente como "collas" - que desarrollan tareas u oficios específicos: "colla de paleteria", "colla de pintores", "colla de encofradores", etc. Durante el auge, la combinación del gran número de migrantes que entraron en el sector con la peculiar organización del trabajo en la construcción tuvo como resultado que las obras se convirtieran en espacios ocupados por un amplio abanico de "collas" étnicas diferenciadas.

En este contexto y desde la prudencia para no caer en análisis totalizadores, la información etnográfica nos indica que se puede identificar la existencia de ciertos "trabajos para inmigrantes". No es que los trabajos ocupados por mano de obra migrada fueran esencialmente diferentes a los ocupados por mano de obra autóctona, sino que, en general, a mayor grado de penosidad, dureza y repetitividad en las condiciones laborales, mayores posibilidades había que ese trabajo lo ejecutara una "colla de inmigrantes". En muchos casos era la misma red social étnica que, en la acogida del recién llegado, le ofrecía un trabajo en el ramo de la construcción.

Llegado el último trimestre de 2007, la sobredimensionada burbuja inmobiliaria estalla y da inicio a la última gran crisis del Estado español. Esto supuso un bloqueo del crédito bancario, un recorte en inversiones públicas y privadas, un estrangulamiento del ciclo especulativo, el cierre de empresas y una masiva expulsión de los trabajadores del sector. Con la llegada de la crisis inmobiliaria, la balanza entre oferta y demanda de fuerza de trabajo quedó notablemente desequilibrada, en otras palabras, se creó un estadio de severa competencia entre trabajadores para poder acceder a los escasos puestos de trabajo que resistieron el declive. Además, al aumento del desempleo se le suman las políticas de austeridad. La enorme cantidad de trabajadores expulsados del ramo de la construcción dificultaba la reconversión profesional de muchos de ellos, aún más teniendo en cuenta el impacto multisectorial de la crisis. El resultado final para muchos obreros fue un estadio sobrevenido de aguda precariedad sin una salida clara. Así, incrementó la presión de un ejército de reserva (Marx 2002 [1867]: 785-787) engrosado en tiempos de auge; consecuentemente, muchos trabajadores acataron trabajar más horas y soportar unas condiciones laborales más duras para acceder a una retribución menor que la que percibían pocos años atrás. Si durante la burbuja encontramos un sector en el que los recién llegados, normalmente, se sitúan en la escala salarial más baja y realizando las tareas de mayor penosidad, cuando llega la crisis, la precariedad se extiende a casi la totalidad de los puestos de trabajo del sector. 
En definitiva, la destrucción de empleo refuerza la percepción de que los obreros compiten entre ellos para acceder a remuneraciones y, de esta manera, paliar la precariedad que sufren. A medida que la crisis y las políticas de austeridad se van interiorizando como un estado de normalidad, se crea el escenario ideal para que surjan concepciones populares sobre cómo deberían ser redistribuidos justamente los empleos y, consecuentemente, quién es reconocido como más o menos merecedor de evitar la precariedad. En este contexto, los obreros muestran una notable tendencia a responder a esta controversia movilizando la distinción simbólica de las comunidades de "trabajadores de aquî" y "trabajadores de fuera". Para fundamentar la distinción, los informantes aplican categorías morales a ambas comunidades, creando de esta manera concepciones que distribuyen el merecimiento en relación al acceso al trabajo, ya sea desde la exclusión, la jerarquización o el repartimiento ecuánime. El resultado final es especialmente complejo para los trabajadores inmigrantes, que deben gestionar situaciones en su cotidianidad sociolaboral que, simultáneamente, los señalan como merecedores e inmerecedores de la precariedad padecida.

\section{LA CREACIÓN DE COMUNIDADES MORALES: PASO INDISPENSABLE ANTES DE DISCUTIR SOBRE (IN)MERECIMIENTO}

Para que, en tiempos de crisis, surjan concepciones populares que distribuyan distintos grados de merecimiento entre obreros autóctonos y migrantes, antes se debe dar una condición, la creación y el refuerzo de la percepción de que los obreros autóctonos y los obreros migrantes forman parte de comunidades morales distintas. Según Yack (2012: 169), nuestro sentido de pertenencia a una comunidad nos dispone a expresar cierto grado de preocupación por el bienestar de un gran número de personas que consideramos que forman parte de un "nosotros" y hacia quienes, si fuera de otro modo, nos sentiríamos indiferentes. Yack (2012: 164) utiliza el concepto de "social friendship" en tanto que ingrediente aglutinador de este "nosotros" y, a la vez, motivador de la búsqueda de un bienestar grupal. El mismo autor advierte que en este proceso de creación y reproducción de comunidades morales encontramos importantes dosis de desorden y arbitrariedad, siendo a menudo el resultado un mosaico confuso de identidades sociales inconsistentes. Dicho esto, la asunción de la variabilidad y maleabilidad inherente a las distribuciones de social friendship no debe dirigirnos a minusvalorar que estar considerado parte de una $\mathrm{u}$ otra comunidad moral tiene impactos objetivos en la vida de las personas. También, la ideología que fundamenta una comunidad moral puede comportar actitudes excluyentes y, en ocasiones, hostiles con las personas consideradas no pertenecientes.

De acuerdo con lo comentado y centrándonos en la dicotomía inmigrante / autóctono, la creación y refuerzo de comunidades morales está fuertemente relacionada con las concepciones de reconocimiento y redistribución. En otras 
palabras, hay una incidencia mutua entre, por un lado, el sistema de etiquetas e identidades socioculturales y, por otro, la posición laboral y las condiciones materiales de existencia. Para el caso de los trabajadores inmigrantes, su identidad estereotipada serviría para reproducir y legitimar su discriminación real en el mercado de trabajo, encubriendo conflictos de base económica. El estereotipo prejuicioso posibilita que la fuerza de trabajo inmigrante sea rechazada para no ocupar los puestos de trabajo socialmente más prestigiosos, con independencia de sus capacidades personales, así como propiciar que sea preferentemente seleccionada para desempeñar las actividades peor remuneradas, inseguras y penosas (Parella 2004: 185). En relación con esto, coincidimos con Elias y Scotson (1994) cuando advierten sobre la insuficiencia de analizar el prejuicio social únicamente desde un enfoque individualizado, apostando por estudiar la figuración formada por los grupos involucrados en el conflicto y los desequilibrios de poder como eje de dicha figuración.

En esta línea, durante la burbuja inmobiliaria se consolidó una organización del trabajo en las obras que reforzó la percepción de que obreros migrantes y autóctonos formaban parte de comunidades morales distintas, pese a compartir espacio de trabajo. Por lo tanto, para comprender desde su base las concepciones sobre (in)merecimiento en contexto de crisis, es necesario conocer las características de la organización del trabajo que, en contexto de auge, posibilitan la creación de distintos grupos simbólicos. Nos referimos principalmente a dos tendencias interrelacionados entre ellas: el cambio en el modelo de contratación y la creciente especialización del trabajo.

Durante la década de los 90 se inició un proceso de metamorfosis del modelo de contratación en el ramo de la construcción que se acentuó y se consolidó en tiempos de burbuja. Las grandes empresas pasaron de incorporar directamente a los obreros mediante contratos indefinidos o contratos de fijo de obra a expulsar progresivamente de sus plantillas el máximo posible de personal fijo, para solamente subcontratar según las exigencias del mercado. Así se sustituían relaciones laborales por relaciones mercantiles, potenciando un nuevo actor del ramo, las empresas subcontratistas. Entonces, la mano de obra inmigrada que empezó a llegar a finales de la década de los 90 ya se incorporaba directamente a un sector cada vez más fragmentado. Aunque, por supuesto, había casos en que dentro de una misma empresa subcontratista se mezclaban obreros de distintos orígenes, en muchos otros coincidía que ciertos grupos étnicos se concentraban en empresas concretas, también que los mismos grupos étnicos creaban pequeñas estructuras de empresa. Por lo tanto, por mucho que migrantes y autóctonos compartieran la obra como espacio físico de trabajo, el hecho de formar parte de diferentes subcontratas provocaba que, en realidad, sus cotidianidades laborales fueran sustancialmente distintas en muchos aspectos: sueldo, horario, organización del trabajo, oficio, costumbres... En este sentido, es común encontrar relatos de autóctonos que aseguran no 
haber cruzado palabra con ningún obrero migrante en los más de seis meses que puede durar una obra. Pues siempre comían en sitios diferentes, salían a horas diferentes y realizaban tareas diferentes. También hemos registrado casos de obreros migrantes que, después de años trabajando en construcción, no habían aprendido a hablar castellano o catalán porque, explicaban, no les era necesario; solo se interrelacionaban con hombres de su colla, esto es, de su país de origen.

Debemos tener presente que, en tiempos de expansión, las grandes acumulaciones de capital fueron posibles gracias a la premisa de que los precios de los inmuebles siempre subían. Entonces, durante el proceso de ejecución de una obra no era tan importante ajustar los costes del proceso de producción como acabar con la mayor celeridad posible para poder colocar el inmueble en el mercado - a un precio progresivamente inflado - y, a continuación, reinvertir los beneficios en un nuevo proyecto. Este contexto desató una lógica hiperproductivista en la que se multiplicaron las empresas subcontratistas que se especializaban en realizar una tarea muy concreta - enyesar, colocar cartón yeso, pintar, derruir, alicatar, etc. -. El razonamiento era que a una mayor especialización del trabajo se correspondía un mayor control de los tiempos de la tarea y también una mayor productividad. En otras palabras, el plus competitivo de las subcontratas especializadas crecía en la medida en que fueran capaces de ofrecer un trabajo en el menor tiempo posible. Además, para eliminar los tiempos muertos y asegurar que los costes de mano de obra se ajustaban perfectamente al trabajo realizado, se potenció el destajo como método de pago.

Hay una anécdota que, bajo distintas formas, aparece recurrentemente en las entrevistas con autóctonos y ejemplifica esta tendencia. Muchos cuentan la sorpresa que sintieron durante el auge al ver que proliferaban en las obras grupos de migrantes que, además de realizar jornadas laborales de diez horas o más, eliminaban el parón para almorzar, traían una olla llena de comida a la obra y se distribuían en turnos de pocos minutos para comer, consiguiendo así que la producción nunca se detuviera. Por otro lado, los autóctonos también participaron de esta vorágine hiperproductivista. Son ejemplo los profesionales que habían desarrollado grandes capacidades en un oficio concreto - enyesar, pintar, alicatar... - y que vieron cómo, durante la expansión, el mercado les ofrecía múltiples oportunidades de empleo en las que el precio por metro estaba muy inflado. En estos perfiles acostumbraban a recaer los famosos sueldos desorbitados de la burbuja.

\section{EL ESTALLIDO DE LA BURBUJA COMO CATALIZADOR DE LAS CONCEPCIONES DE (IN)MERECIMIENTO}

Hemos comentado que el hecho de sentirse parte de una comunidad moral implica cierto grado de consideración hacia aquellos que consideramos iguales. 
Si nos focalizamos únicamente en el sentimiento de social friendship, veremos que por sí mismo este no debería resultar problemático, es decir, esperar el bienestar de otras personas no parece conllevar controversia moral alguna. Igualmente, Yack (2012: 175) nos advierte de que la creación de una comunidad hacia la que se muestra cierta consideración implica, inevitablemente, que habrá sujetos que queden excluidos de ella, es decir, sujetos percibidos como no tan merecedores - o directamente inmerecedores - de la consideración que procuran los lazos de social friendship. Entonces, uno de los retos teóricos alrededor del estudio de las comunidades morales es el de descubrir cuáles son las circunstancias sociales que favorecen que una comunidad moral pase de percibir a los sujetos externos como un simple "otros" - sencillamente menos merecedores de bienestar - a percibirlos como un "ellos" - una amenaza para "nuestro" bienestar -, integrando así dosis de confrontación. Para nuestro caso, hemos visto que todo el proceso de configuración de grupos simbólicos - "nosotros" y "otros" - se engendró durante la etapa de expansión, mediante el cambio del modelo de contratación y la especialización del trabajo. Pero fue el estallido de la burbuja el catalizador que facilitó el cambio hacía una lógica de "nosotros" y "ellos". Con la precariedad surgieron ciertas concepciones que señalaban al grupo de trabajadores inmigrantes como sospechosos de ser inmerecedores de recursos y oportunidades para paliar la crisis, en beneficio de los trabajadores autóctonos. En respuesta, otras concepciones defendían que todos los trabajadores tienen igual derecho a conseguir trabajo y huir de la precariedad. Veamos el testimonio de Carlos: ${ }^{4}$

"Al principio [durante el auge] estábamos todos y no había problema, cada uno a lo suyo, pero luego [llegada la crisis] ya solo contrataban a gente de esta, porque era mano de obra barata y eran mucha gente y lo hacían así, realmente nos jodió mucho, nos echaron". 5

Mientras que durante los tiempos de bonanza había posibilidades suficientes para que, en términos generales, los obreros del ramo consideraran que estaban siendo recompensados dignamente por su trabajo, a partir de 2007 se establece una realidad simbólica parecida a un juego de suma cero. En este estadio, se fomenta que los sujetos interpreten varios episodios cotidianos en términos de competición entre comunidades morales. Es este contexto el que facilita el surgimiento de concepciones de (in)merecimiento.

4 Todos los nombres presentados en este artículo han sido modificados para preservar el anonimato de los informantes.

5 Carlos tiene 32 años, es nacido en Cataluña e hijo de padre valenciano y madre andaluza. Empezó a trabajar en la construcción a los 13 años, en la empresa familiar. 


\section{EL TRABAJADOR INMIGRANTE INMERECEDOR: CONSTRUIDO COMO COMPETIDOR DESLEAL}

En varias entrevistas con trabajadores autóctonos aparecen reflexiones que señalan el exceso de mano de obra absorbida por el ramo durante el auge como una de las principales causas de la crisis. Así lo expresaba Juan: "éramos muchos, cada vez había más gente, no era normal, al final tenía que petar porque no era normal". ${ }^{6}$ Adicionalmente, la reflexión de la superabundancia de trabajadores en el sector se vincula a la idea de que el grupo de obreros inmigrantes, ofreciéndose a realizar trabajos a un bajo precio, acabó provocando que los salarios bajaran drásticamente y que estallara la burbuja. Juan sigue con su argumento:

"Si no hubieran llegado todos los moros, la cosa no hubiera petado porque no habríamos llegado tan lejos con esto del boom, si ellos están dispuestos a trabajar a muy bajo precio, sin asegurar y sin derechos laborales, y nosotros no... Es normal, si a ti te viene uno de aquí y te dice que cobra $2,5 €$ el metro y al lado hay un moro que te lo hace a $1,5 €$, pues coges al moro, $1,5 €$ el metro es una miseria, no es justo, pero si a los moros ya les va bien con eso pues es lo que hay, no puedes hacer nada".

En muchos de los discursos que van en esta línea existe una minimización de los impactos que sufrieron el grupo de inmigrantes con la crisis. Mediante expresiones como "nos echaron" o "al final solo quedaron ellos", se asume que, una vez llegada la crisis, la gran mayoría de obreros inmigrantes consiguió mantenerse en el sector trabajando; en contraposición, los trabajadores autóctonos son los expulsados y principales perjudicados. El trabajo de campo señala que, efectivamente, pudo existir durante los primeros años de recesión un proceso de sustitución de mano de obra autóctona por mano de obra inmigrada, consiguiendo así un abaratamiento de los costes de producción. Por otro lado, tanto los datos presentados en la introducción como la misma etnografía también apuntan a que una gran cantidad de obreros inmigrantes se vieron expulsados del sector a partir de 2007 y siquiera tuvieron la oportunidad de acceder a empleos precarios. Ambas realidades son compatibles; al presentarle esta objeción a Juan emerge la noción de merecimiento vinculada a la competencia desleal:

"[Xavier] - Pero también hubo muchos marroquíes que perdieron el trabajo con la crisis y lo pasaron muy mal. 
[Juan] - Claro, pan para hoy y hambre para mañana. El que trabajaba a 1,5 $€$ y después perdió el trabajo que se joda, se lo merece, que lo hubiera pensado antes".

La noción de merecimiento ligada a la competencia desleal no solo inunda los discursos, sino que la crispación que les generaba a los trabajadores autóctonos tener que experimentar cotidianamente un descenso en las ofertas y en el precio del trabajo también provocaba conflictos laborales. Carlos narra uno de ellos:

"En la última obra que estuve, ya con la crisis, había de todo, chinos, pakistanís, marroquís, españoles... Y había muchos conflictos, claro, porque nos quitaban la faena realmente, si se la daban a ellos era menos para nosotros y no podíamos competir porque ellos eran el triple que nosotros y la mano de obra muy barata, pues había conflictos y racismo sí. [...] En mi caso fue que subcontrataron a muchos chinos para poner obra vista, yo iba replanteando la obra vista y mi colla iba haciendo, íbamos a metros. Claro, nosotros hacíamos mejor los metros y hacíamos más, pero el sueldo de uno mío eran cuatro suyos, al final ocho manos hacen más que dos y claro, era imposible, aunque luego tenías que ir a arreglarles sus fallos y todo, pues bajaron los sueldos, pagaban el metro a menos porque ellos podían hacer más con menos. De hecho, en las dos obras que estuve vivían 20 personas en un piso, alquilaban un piso y metían 20 ahí y luego en la obra echaban 14 o 16 horas, la obra nunca paraba, porque como eran tantos se iban turnando, claro, no podíamos competir con eso, era imposible. [...] De hecho nosotros hemos tenido conflictos en la obra de esto, de que el gruista [español], de coger y venga, mortero para todo el mundo... venía un cubilote lleno de mortero y nos servía a los españoles primero y a los chinos los últimos, los teníamos ahí parados y se roneaba [eternizaba] para servirles [proporcionar mortero], les jodía mucho porque no podían trabajar y se enfadaban".

Hay testimonios que explican anécdotas parecidas. Por ejemplo, que el gruista hacía coincidir siempre su horario de almuerzo con el momento en que tocaba servir material a los obreros chinos. Según este testimonio, el enfado de los obreros chinos era notable porque ellos no tenían contemplado parar la producción para almorzar, pero, al no tener material, se veían obligados a hacerlo.

Si bien el término de merecimiento no aparece explícitamente en los relatos de las anécdotas, sí que, en ambos casos, los obreros autóctonos las explican utilizando una retórica de impartición de justicia. Ellos fijaban la competencia desleal como el motivo por el que los obreros inmigrados merecían este agravio comparativo en el trato por parte del gruista. De hecho, hay un fuerte nexo entre este episodio etnográfico y lo que Scott (2000) llamó la infrapolítica 
de los grupos subordinados. Concretamente, con este término el autor quería "designar una gran variedad de formas de resistencia muy discretas", mostrando así "que ni las formas cotidianas de resistencia, ni la insurrección ocasional se pueden entender sin tener en cuenta los espacios sociales cerrados en los cuales esa resistencia se alimenta y adquiere sentido" (Scott: 2000: 44-45). Aunque en estrictos términos de jerarquía laboral en la obra, los trabajadores inmigrantes se situaban normalmente en una posición de igualdad o subordinación en relación a los autóctonos, los boicots que perpetraban los trabajadores autóctonos hacia la productividad de los grupos inmigrantes se justificaban desde un discurso en el que los autóctonos se concebían como los más perjudicados por un pacto implícito de mutuo beneficio entre empresario e inmigrante, en el que el empresario conseguía reducir costes en tiempos de recesión y el inmigrante conseguía acceder una remuneración en tiempos de precariedad. Tal que así lo explica Carlos:

"Yo no soy racista, pero si me meto en este tema, sí que he sido racista y aún si me acuerdo me cago en los chinos, porque realmente... No en ellos, porque luego lo pienso fríamente y verdaderamente quien tiene la culpa es el que contrata, que es el que no da igualdad. Porque yo siempre lo he dicho, si un chino o un marroquí o un árabe trabaja igual que yo, hace la misma faena que yo, la hace igual de bien y todo, que le paguen mi sueldo, se lo merece, ya está. Pero no que contrates a cinco y le des una mierda, porque a ellos ya les va bien y no te dirán nada, pero se dejan la espalda igual, no lo veo bien que los contraten porque necesitan trabajar realmente y trabajan en condiciones de mierda, sin seguro".

En este párrafo, Carlos diferencia entre el trabajador inmigrante que compite lealmente y que merece sus condiciones laborales - "los que trabajan igual que yo" -, y el que ejerce la competencia desleal y merece reprimenda - "a los que ya les va bien que les paguen una mierda" -. Es evidente que esta diferenciación no hace más que invisibilizar, primero, los desplazamientos forzados por las mencionadas dinámicas neoliberales de desposesión en el Sur global y, segundo, las dinámicas de incorporación de dicha mano de obra desplazada en los segmentos más precarios del Norte global.

Aun así, esto no impide que algunos de los trabajadores inmigrados ratifiquen e incluso incorporen esta violencia discursiva. Proponemos como ejemplo a Salik. ${ }^{7}$ Él cuenta que, en varias ocasiones, había trabajado en obras de

7 Salik tiene 42 años, es nacido en Marruecos. Llegó a Cataluña en 2005 y fue entonces cuando hizo sus primeros trabajos en el sector de la construcción. Declara convencido que quiere evitar trabajar en las obras. Aunque ha intentado buscar alternativas laborales, siempre acaba volviendo a la construcción cuando no tiene otra opción mejor. 
mantenimiento de la vía pública, siempre contratado por un familiar suyo, que era autónomo. Salik definía las tareas que realizaba en ese tipo de obras como duras, exigentes y sin descanso. Él aseguró que, en la medida en que tuviera opción, siempre evitaría trabajar bajo las órdenes de algunos de sus paisanos autónomos. Apuntaba que, aunque fueran familiares, el buen trato no estaba garantizado. Al contrario, su experiencia apuntaba a que los marroquíes eran los jefes que más exigían y los que peor pagaban. En contraste, mencionaba el caso del trabajo en empresas grandes, en las que se pagaba un poco más y las condiciones eran mejores. Después de narrar sus vivencias, llegaba el momento en que Salik admitía ver comprensible que existiera cierto rechazo hacía el trabajador marroquí en la construcción, por ser el causante de una normalización de las condiciones laborales precarias, las cuales los españoles sí que eran más reticentes de aceptar.

\section{EL TRABAJADOR INMIGRANTE MERECEDOR: CONSTRUIDO COMO ALTERIDAD}

Hemos visto que, en el núcleo de las concepciones de inmerecimiento de acceso al empleo dirigidas a los trabajadores inmigrantes, encontramos el argumento de la competencia desleal. Hay ciertos trabajadores inmigrantes que rechazan las argumentaciones que los clasifican como competidores desleales; ellos señalan que realizaban el mismo tipo de trabajo tanto antes de la crisis como una vez llegada esta. Consecuentemente, lo que se modificó a partir de 2007 no fue su actitud en relación al mercado de trabajo, sino el mercado en sí. Veamos las palabras de José:

“No, no he visto racismo en España yo. Pero yo cuando llegué aquí [2001] necesitaba dinero para traer a mi familia y a mí nunca me ha importado el trabajo, si se tiene que barrer pues se barre y si con barrer no llega, se busca otra cosa. Después cuando llegó la crisis todos estos que decían que no querían hacer trabajos así [barrer] se empezaron a quejar de que ellos merecían más el trabajo por ser españoles y que los inmigrantes les quitábamos el trabajo. Claro, ahora, cuando ya llevaba siete años barriendo, ahora te lo quito, en eso sí que vi racismo". ${ }^{8}$

José cuenta que en su etapa como barrendero en la obra nunca llegó a cobrar más de 1200 euros ni tuvo opción de mejorar sus condiciones. Su sueldo y sus oportunidades eran mucho peores que las de sus compañeros autóctonos y

8 José tiene 58 años, es nacido en Paraguay. Llegó a Cataluña en 2001. Antes de quedarse en paro por la crisis paraguaya de 1995, él trabajaba como técnico de producción por una gran empresa constructora. Al llegar aquí solo pudo dedicarse a tareas de limpieza y peonaje básico en el sector de la construcción. 
destaca que, entonces, nadie le acusaba de quitarle el trabajo a nadie. Él ve contradictorio e inoportuno que los mismos a los que durante el auge les daba igual que él cobrara por debajo de la media, con la crisis empezaran a señalarle como ocupante ilegítimo de un trabajo que merecía más un español por el simple hecho de serlo. Según José, él y muchos otros inmigrantes merecieron permanecer en sus trabajos cuando estalló la burbuja porque ya habían estado realizando ese tipo de trabajos cuando la mayoría de autóctonos los rechazaban.

Las reflexiones de José nos remiten a un debate teórico sobre merecimiento en el que distintos grupos de sujetos - autóctonos e inmigrantes - remarcan su membresía a distintas comunidades morales - españoles y trabajadores precarios, respectivamente -, pero todos con el objetivo común de, en tiempos de crisis, autoposicionarse como merecedores de los puestos de trabajo. José viene a declarar que no es la membresía nacional española la que determina quién es más merecedor de un puesto de trabajo, sino que el criterio de merecimiento se debería medir según la membresía de cada persona - independientemente de su lugar de origen - a la comunidad moral formada por las personas que ya antes de la crisis se dedicaban al trabajo precario. Siguiendo con José: "Si ya me pasé siete años [durante la burbuja] barriendo, ahora no me quites la escoba cuando tú no tienes trabajo [llegada la crisis], ¿entiendes?" De esta forma, José da la vuelta al conocido recurso de que "los migrantes merecen menos por haber llegado más tarde". Su experiencia le enseña que, en el mundo del trabajo precario del ramo de la construcción, el último en llegar - o sea el foráneo - fue el trabajador autóctono.

Este mismo debate lo detectan Chauvin, Garcés-Mascareñas y Kraler (2013: 81) cuando señalan que, dentro del actual modelo económico, existen fricciones entre las visiones del empleo entendido como obligación o como privilegio. Dicha fricción de visiones actúa con especial intensidad cuando el grupo tratado son los inmigrantes. Por un lado, el sistema económico neoliberal, en tanto que workfare regime, sitúa al empleo en general - y el empleo migrante en particular - como una obligación cívica que distingue entre residentes merecedores y residentes inmerecedores de la precariedad. Por otro lado, desde ciertas visiones ideológicas restrictivas hacía el fenómeno de la migración e igualmente insertas en el sistema económico neoliberal, se considera el empleo como un privilegio cívico basado en una membresía nacional preexistente y que, por lo tanto, excluye al grupo de migrantes. Siguiendo las reflexiones de Chauvin, Garcés-Mascareñas y Kraler (2013: 82), el actual sistema económico neoliberal se sostiene por una ética del trabajo particular, construida desde el empleo remunerado, la autosuficiencia y la capacidad de adaptación a unos mercados laborales precarios y flexibles.

Nuestra etnografía ratifica que estas características moldean también los marcos culturales y que la mayor o menor adaptación a dicha ética del trabajo se acostumbra a traducir en valoraciones sobre el grado de merecimiento de 
derechos de los inmigrantes - cualificados o no cualificados, de primera o segunda generación, regulares o irregulares -. En pocas palabras, las concepciones de merecimiento se miden a partir de la capacidad o voluntad que individualmente muestren estos sujetos para convertirse en este tipo de mano de obra barata y flexible. Este es el argumento que moviliza José para defender que él merece mantener su trabajo y evitar la precariedad. Pero no debemos olvidar que, en este proceso, la integración y la estigmatización - o el merecimiento y el inmerecimiento - son dos caras de la misma moneda, pues el obrero migrado está integrado en tanto que explotado. Es decir, el obrero inmigrante se erige a sí mismo como merecedor de trabajo por haberse integrado al mercado - precario - de su lugar de destino, pero este mismo proceso le señala como inmerecedor a ojos de otros trabajadores, por ser competidor desleal. En definitiva, su posición en el sistema de producción y en la jerarquía sectorial los confronta simultáneamente a discursos de merecimiento e inmerecimiento.

Esta contradicción era expresada elocuentemente por Salik: "Hagas lo que hagas, está mal, si trabajas, porque trabajas, y si no trabajas, porque no trabajas". Con esta breve reflexión, él denuncia que se ha encontrado en callejón sin salida. Para Salik y para muchos otros inmigrantes, su grado de integración a la sociedad española normalmente es evaluado según su predisposición a trabajar, o sea, claudicar frente un mercado que genera empleos con condiciones precarias y sueldos bajos. Pero, por otra parte, este proceso de integración mediante claudicación puede enfrentar al inmigrante a situaciones de señalamiento o rechazo en el ámbito laboral, en el que se le acusa de competencia desleal y de estar "quitándole el trabajo a los españoles".

El fundamento en el que se sostienen tanto las concepciones de merecimiento como de inmerecimiento que acabamos de presentar es la construcción del sujeto inmigrado en tanto que alteridad. Así lo subraya Calavita:

“... su localización [la del inmigrante] en la economía reproduce la otredad desde dentro, ya que el status de los inmigrantes de subclase de trabajadores con sueldos bajos y condiciones de trabajo deplorables impide la incorporación plena a la comunidad nacional. De hecho, no es tan sólo que las desigualdades globales históricas han producido sujetos postcoloniales que hoy proporcionan trabajo barato a los poderes del primer mundo; dichas desigualdades y dichos sujetos postcoloniales son reproducidos desde dentro" (Calavita 2006: 198).

Hasta ahora hemos analizado detalladamente el proceso de reproducción material y simbólica de inmigrantes inmerecedores en el ramo de la construcción de Barcelona y su área metropolitana. Las particularidades de este sector - básicamente, fragmentación estructural y comportamiento cíclico - han resultado clave para que se generaran realidades sociolaborales que tenderán 
a representar al trabajador inmigrante como alteridad. En este sentido, nos encontramos en un estadio en el que la escasez de trabajo y la precariedad extendida con la crisis se contemplan como una injusticia que enfrenta a las comunidades morales de obreros autóctonos y obreros migrantes. Estas concepciones de injusticia confrontativa entrelazan cuestiones de reconocimiento y de redistribución; así se crea un círculo vicioso en el que se retroalimentan ciertas distinciones simbólico-morales y ciertas condiciones objetivas de producción, ambas de carácter excluyente. También hemos comprobado como las concepciones de (in)merecimiento nos permiten revelar que las identidades socioculturales de tendencia hostil y la organización de la producción basada en la mano de obra barata, flexible y disponible se recrean. Finalmente, podemos afirmar que la construcción barcelonesa es un ramo principalmente estructurado desde una ética y una organización predominantemente neoliberal.

\section{EL TRABAJADOR MERECEDOR: CONSTRUIDO DESDE UNA EPISTEMOLOGÍA DE LA NECESIDAD}

A estas alturas, nos preguntamos: ¿existen entre los obreros de la construcción concepciones de merecimiento que consigan articularse superando el obstáculo de la alterización? La respuesta es sí. Encontramos varios informantes que abogan por una repartición ecuánime y no hostil del merecimiento. La raíz epistemológica desde la cual es posible trazar concepciones de merecimiento alternativas a la lógica neoliberal es la necesidad.

Procedamos con el relato de Abdou:

“Tengas contrato o no, lo que hace que te puteen es la necesidad, la necesidad te putea, porque tienes que trabajar sea como sea. Yo en los pisos estos, en la obra de los pisos, cuando estaba ahí, yo necesitaba mi papeles, pagar la seguridad social, si no los voy a perder. Si no, no se renuevan. Y como que este me puteaba mucho, una vez tuve los papeles y dije: 'Esto tiene que parar, porque yo estoy trabajando tío, me estas puteando y... tengo mi dignidad. Eres un racista. Porque aunque seas español, tú un día a lo mejor también te putean por necesidad'".?

En este fragmento, Abdou aparta el foco de la competencia desleal, de la ética neoliberal del trabajo o de la membresía nacional y lo desplaza hasta apuntar a la necesidad como única centralidad del conflicto. En comentarios

9 Abdou tiene 39 años, es nacido en Senegal. Llegó a Cataluña en 2006. En su país de origen se dedicaba a múltiples oficios, principalmente la pesca. Al llegar a Cataluña estuvo trabajando para una pequeña empresa constructora hasta que se quedó sin empleo en 2008. En 2012 consiguió legalizar su situación en el Estado español, denunciando a su empleador. 
posteriores, él añade el ingrediente del merecimiento, vinculándolo a derechos morales superiores. Concretamente, él afirma que cualquier persona que lo necesite tiene derecho a trabajar dignamente. Si en el actual contexto de crisis en el sector de la construcción nos agarramos a esta declaración de máximos y la llevamos hasta las últimas consecuencias, nos daremos cuenta que el actual modelo de producción no está orientado a ofrecer trabajo digno a los obreros necesitados. Por lo tanto, inevitablemente, la declaración de Abdou nos impele a cuestionar el sistema de producción del ramo y el marco cultural laboral que impera en este, ambos basados en la competencia, la flexibilidad y la precarización como vías para lograr un abaratamiento de la mano de obra.

La universalidad y la particularidad deben ser concebidas desde una relación dialéctica (Harvey 1996: 362) y, justamente, una epistemología de la necesidad nos evidencia que existe un nexo entre determinadas injusticias vividas en la cotidianidad de los obreros y los colosales procesos de acumulación de capital, ambos fenómenos insertos en el seno del ramo. La necesidad como noción epistemológica también permite que la construcción de concepciones de merecimiento facilite alianzas basadas en la similitud (Harvey 1996: 361), superando los procesos de alterización de sujetos y difuminando las más que cuestionables fronteras entre las comunidades morales de trabajadores autóctonos e inmigrantes. Precisamente en esta línea reflexiona Pepe:

"Es que parece que nos hayamos olvidado de dónde venimos. Hay gente que dice que echaría a todos los extranjeros, pero a ver... isi aquí somos todos extranjeros en un momento dado! Hay derecho a que la gente se vaya y se busque la vida, lo que pasa es que tiene que haber una organización por parte del gobierno y las [grandes] empresas y por parte de los que organizan todo esto, una organización mejor. [...] Lo que pasa es que de los extranjeros se aprovechan, están acostumbrados a cobrar una miseria, a parte se meten ocho en un piso y les da igual. Pero muchos que dicen esto se olvidan que cuando llegaron aquí también iban con una mano delante y otra detrás. Yo vengo de familia andaluza y mis padres se morían de hambre en el pueblo, por eso se vinieron aquí, es que se morían de hambre. Y cuando llegaron aquí no se metieron en un chalet. Es lo mismo". ${ }^{10}$

En tiempos de crisis, la escasez de puestos de trabajo en el sector de la construcción de Barcelona y área metropolitana deriva en claras injusticias económicas y de reconocimiento (Fraser 2000) para los obreros. Con sus palabras, Pepe introduce una visión estratificada del ramo, en la que se atribuye la responsabilidad de estas injusticias a los actores situados en los altos estratos

10 Pepe tiene 56 años, es nacido en Andalucía. Llegó a Cataluña en 1970. Dio sus primeros pasos en el sector de la construcción a mediados de los 80 y desde entonces siempre ha trabajado como albañil. 
de poder - gobierno y grandes empresas -. También contrapone la reclamación integradora del derecho de toda la gente a "buscarse la vida". Las palabras de Pepe nos remiten al texto de Aramburu (2002: 65) sobre la construcción de otredades en Barcelona. Él aplica la noción de táctica - similar a "buscarse la vida" - entendiéndola como el arte de los débiles, es decir, acciones dirigidas a tomar ventaja en un campo desfavorable. El autor nos advierte que las tácticas no siempre cuestionan las premisas del orden socioeconómico, por el contrario, pueden fortalecer las desigualdades materiales y simbólicas. Los ejemplos del inmigrante como competencia desleal o como alteridad merecedora confirman las tesis de Aramburu.

Así pues, compartimos las aproximaciones de Fraser cuando explica que "la cultura y la economía política siempre están imbricadas la una con la otra; y prácticamente todas las luchas en contra de la injusticia, si se entienden adecuadamente, conllevan reivindicaciones tanto de redistribución como de reconocimiento" (Fraser 2000: 128). Aun así, refiriéndonos al trabajo etnográfico presentado, no podemos obviar que es cuando se parte de la necesidad, como noción arraigada a la economía política, cuando mayores grados de ecuanimidad se alcanzan en el reconocimiento de todos los obreros como merecedores de acceder a un puesto de trabajo y evitar la precariedad. De esta forma mantenemos en primer plano un hecho que nunca debería olvidarse: históricamente, el sector de la construcción en la provincia de Barcelona ha sido un espacio de acogida de migrantes y necesitados (Mota 2010).

\section{CONCLUSIONES}

En este artículo hemos constatado que la noción de merecimiento es un vehículo analítico muy pertinente para acercarnos a las problemáticas cotidianas de nuestros informantes. Situándonos en el sector de la construcción de Barcelona y área metropolitana durante los tiempos de crisis, el merecimiento nos facilita alcanzar tres objetivos teóricos que resultan indispensables para poder comprender las conflictividades entre los trabajadores autóctonos e inmigrantes. El primero es la interpelación a las distintas escalas de análisis, interconectándolas entre sí y mostrando la gradación de relaciones sociales que vinculan los fenómenos estructurales con las vivencias particulares. Mediante los discursos que daban respuesta al interrogante de "iquién merece acceder preferentemente a los escasos puestos de trabajo?” y “¿quién es menos merecedor de la precariedad que se ha extendido con la crisis?”, los obreros viajaban constantemente de sus más específicas experiencias cotidianas a las más generales dinámicas de organización de la producción del ramo y a los acontecimientos macroeconómicos vinculados al comportamiento cíclico de la construcción.

En segundo lugar, el merecimiento permite introducir el ingrediente de la moralidad en el proceso de creación de grupos simbólicos, dando lugar a 
las comunidades morales. Aunque las difusas fronteras y pertenencias a las comunidades morales, en muchas ocasiones, contengan importantes dosis de arbitrariedad y volubilidad, no se puede obviar el impacto objetivo que estas tienen en los procesos de exclusión y jerarquización de sujetos en un contexto de precariedad. El merecimiento nos da pistas fiables sobre el origen estructural de las distintas comunidades morales y también sobre la evolución de las relaciones - más o menos hostiles - entre ellas.

Por último, mediante la noción de merecimiento podemos ahondar etnográficamente en el diálogo que Fraser (2000) establece entre las cuestiones socioculturales vinculadas al reconocimiento y las cuestiones materiales vinculadas a la redistribución. De acuerdo con el último punto, la efectividad de los procesos de valoración social y la mejora de las condiciones materiales de existencia de los obreros del sector de la construcción dependerán de si los mismos implicados se focalizan en las necesidades como principal criterio de distribución del merecimiento. La inmensa mayoría de las reflexiones nacidas desde la noción de necesidad acababan en concepciones de justicia que, tanto en términos de reconocimiento como de redistribución, contenían un espíritu integrador. Por el contrario, hemos visto como los demás caminos nos llevan a concepciones de merecimiento que terminan en reclamaciones de mejoras excluyentes o parciales. Primero, el criterio de la competencia desleal esconde la precariedad que el mismo sistema económico neoliberal impone a los obreros y que los obliga a vender su fuerza de trabajo a cambio de un bajo precio. Segundo, los criterios de membresía - ya se refiera esta a la nación o al tipo de trabajo - normalizan la existencia de unos estratos laborales engendrados en la penosidad laboral y los sueldos míseros, solamente discutiendo acerca de quién debe ocuparlos.

Cerrando el artículo, el trabajo de campo apunta hacia una epistemología de las necesidades como la estrategia más óptima en el establecimiento de alianzas que, sin invisibilizar las diferencias socioculturales y materiales existentes, se marcarían un objetivo común: la socialización y puesta a disposición de los recursos acumulados en unas pocas manos y el consecuente aplacamiento de la precarización.

\section{BIBLIOGRAFÍA}

ARAGHI, Farshad, 2009, "Accumulation by displacement: global enclosures, food crisis, and the ecological contradictions of capitalism", Review: A Journal of Fernand Braudel Center, 32: 113-146. 
ARAMBURU, Mikel, 2002, Los Otros y Nosotros: Imágenes del Inmigrante en Ciutat Vella de Barcelona. Madrid, Ministerio de Educación y Cultura.

CALAVITA, Kitty, 2006, "Contradicciones estructurales en la política de inmigración: los casos de Estados Unidos y la Europa del Sur", Revista Española de Investigaciones Sociológicas, 116 : 185-212.

CHAUVIN, Sébastien, Blanca GARCÉS-MASCAREÑAS, y Abert KRALER, 2013, "Employment and migrant deservingness", International Migration Review, 51 (6): 80-85.

CHAUVIN, Sébastien, y Blanca GARCÉS-MASCAREÑAS, 2014, "Becoming less illegal: deservingness frames and undocumented migrant incorporation", Sociology Compass, 8 (4): 422-432.

DE LA GARZA TOLEDO, Enrique, 2012, "La subcontratación y la acumulación de capital en el nivel global”, en J.C. Celis Ospina (coord.), La Subcontratación Laboral en América Latina: Miradas Multidimensionales. Bogotá, Clacso, 121-134.

DEL ÁGUILA LACOSTE, Álvaro, 2015, “'El que no se la banca, mejor que se dedique a otra cosa': riesgo, masculinidad y clase social entre trabajadores paraguayos en la industria de la construcción del Área Metropolitana de Buenos Aires", Runa, 36 (1): 51-72.

ELIAS, Norbert, y SCOTSON, John L., 1994, The Established and the Outsiders. Londres, Thousand Oaks; New Delhi, Sage Publications.

FRASER, Nancy, 2000, “¿De la redistribución al reconocimiento? Dilemas de la justicia en la era 'postsocialista'”, New Left Review, 0: 126-253.

HARVEY, David, 1996, "Class relations, social justice, and the political geography of difference”, en D. Harvey, Justice, Nature, and the Geography of Difference. Cambridge, Blackwell Publishers, 334-365.

MARX, Karl, 2002 [1867], “El proceso de acumulación de capital”, en K. Marx, El Capital: Libro I. México, DF, Siglo XXI Editores, 1-955.

MOTA, José Fernando, 2010, Mis Manos, Mi Capital: Los Trabajadores de la Construcción, las CCOO y la Organización de la Protesta en la Gran Barcelona (1964-1978). Valencia, Editorial Germania.

NAREDO, José Manuel, 2009, "La cara oculta de la crisis: el fin del boom y sus consecuencias”, Revista de Economía Crítica, 7: 11 8-133.

NAREDO, José Manuel, 2010, “Comunicación al coloquio sobre urbanismo, democracia y mercado: una experiencia española (1970-2010)”, presentada en el Instituto de Urbanismo de París.

PARELLA, Sònia, 2004, "Reclutamiento de trabajadoras inmigrantes en las empresas de servicios de proximidad en el Área Metropolitana de Barcelona”, Revista Española de Investigaciones Sociológicas, 108 (04): 179-198.

PINK, Sarah, Dylan TUTT, y Andrew DAINITY, 2012, Ethnographic Research in the Construction Industry. Nueva York, Routledge.

SCOTT, James, 2000, Los Dominados y el Arte de la Resistencia. México, DF, Ediciones Era.

YACK, Bernard, 2012, "The moral value of contingent communities", en B. Yack, Nationalism and the Moral Psychology of Community. Chicago y Londres, The University of Chicago Press, 161-183. 